\title{
EL ELEMENTO SITUACIONAL DE VIOLACIÓN MASIVA DE DERECHOS HUMANOS DE LA DEFINICIÓN AMPLIADA DE CARTAGENA: HACIA UNA APLICACIÓN EN EL CASO VENEZOLANO
}

\author{
THE SITUATIONAL ELEMENT OF MASSIVE VIOLATION OF HUMAN \\ RIGHTS IN THE EXTENDED REFUGEE DEFINITION OF CARTAGENA: \\ TOWARDS ITS APPLICATION TO THE VENEZUELAN CASE
}

\author{
ISABel BerganZa SeTiÉN* \\ CÉCILE Blouin ${ }^{* *}$ \\ Luisa Feline Freier ${ }^{* * *}$
}

\begin{abstract}
RESUMEN: En un contexto de liberalización de sus marcos normativos, la mayoría de los países en América Latina han incorporado la definición ampliada de refugiado de la Declaración de Cartagena de 1984 en su legislación doméstica. Sin embargo, esta definición se ha aplicado pocas veces. Frente al éxodo de personas venezolanas, y en un contexto de endurecimiento de las políticas migratorias en general, y hacia la población venezolana en especial, es necesario discutir sobre la posible aplicación de esta definición a dicha población. Sin negar la importancia de las implicancias políticas de la aplicación de Cartagena, este artículo aborda, desde una mirada jurídica, los retos para conceptualizar sus elementos situacionales, enfocándose en el de violación masiva de derechos humanos. Para ello, el artículo propone desarrollar un marco conceptual de este elemento situacional y su aplicación al caso venezolano.
\end{abstract}

Palabras clave: Venezuela, violación masiva de derechos humanos, desplazamiento forzado, Declaración de Cartagena, definición ampliada de refugiado

ABSTRACT: In the context of the liberalization of their regulatory frameworks, most countries in Latin America have incorporated the extended refugee definition of the 1984 Cartagena Declaration in their domestic legislation. However, this particular definition has only been applied in very few cases. In light of the mass displacement of Venezuelan migrants, and within a context of toughening migration policies, in general, and directed towards the Venezuelan population, in particular, it is necessary to discuss the possible application of

\footnotetext{
Doctora. Vicerrectora Académica. Código Orcid 0000-0003-3611-7625. Universidad Antonio Ruiz de Montoya. Av Paso de Los Andes 970, Pueblo Libre. isabel.berganza@uarm.pe

** Magíster. Código Orcid 0000-0002-4499-1737. Instituto de Democracia y Derechos Humanos de la Pontificia Universidad Católica del Perú (IDEHPUCP) y Facultad de Derecho de la PUCP. Av. Universitaria 1801, San Miguel. cblouin@pucp.edu.pe

*** Doctora. Código Orcid 0000-0002-4653-4812. Centro de Investigación de la Universidad del Pacífico y Departamento Académico de Ciencias Sociales y Políticas. Jirón Luis Sánchez Cerro 2050, Jesús María. lf.freierd@up.edu.pe

Las autoras agradecen a Francisco Mamani Ortega, Génesis Vargas, Adriana Alzamora, Natalia Koper, Weronika Betta, Gabriela Ramos, asistentes de investigación del Idehpucp por el apoyo en la búsqueda y resúmenes de fuentes, así como Valeria Arón y Soledad Castillo, asistentes de investigación del CIUP por la ayuda en la revisión del texto. Asimismo, agradecen a Francisco Mamani y los comentarios recibidos como parte del proceso de revisión de este artículo por parte de los evaluadores
} 
the extended definition to this population. Without denying the importance of the political implications of such application, this article addresses the challenges in conceptualizing its situational elements from a legal perspective, specifically focusing on the massive violation of human rights. To do so, we propose a conceptual framework for understanding this particular situational element and its application to the Venezuelan case.

Keywords: Venezuela, mass human rights violation, forced displacement, Cartagena Declaration, extended refugee definition.

\section{INTRODUCCIÓN}

Cada vez es más evidente que el éxodo de personas venezolanas que comenzó en el año 2014 se está convirtiendo en el mayor desplazamiento internacional forzado de personas en la historia de América Latina. La profundización de la crisis política, económica y humanitaria en Venezuela ha llevado a un desplazamiento masivo de venezolanos hacia diversos países de la región. Las estimaciones de los números de emigrantes venezolanos son imprecisas: si bien la Plataforma Regional de Coordinación Interagencial para Refugiados y Migrantes de Venezuela, a inicios de abril de 2020, registraba la cifra de 5,093,987 millones de venezolanos/as migrantes, refugiados/as y solicitantes de asilo ${ }^{1}$ fuera del país, esta deja de lado a las personas con estatus migratorio irregular y a las que continúan dejando Venezuela diariamente.

Llama la atención que solamente una pequeña parte de los venezolanos desplazados ha presentado solicitudes de asilo. Los motivos pueden ser diversos: desconocimiento, estigma, o tiempos de espera ${ }^{2}$. Aun así, las solicitudes de asilo de venezolanos se han incrementado notoriamente cada año desde 2014. Según la data del Alto Comisionado de las Naciones Unidas para los Refugiados (ACNUR), los números de solicitudes en todo el mundo aumentaron de 3,975 en 2014 a 650,606 en 2019. En Perú, a fines de diciembre de 2019, 482,571 individuos habían solicitado asilo; 129,988, en Brasil, a fines de noviembre ; y 108,942, en los Estados Unidos hacia finales de diciembre de este año ${ }^{3}$. Hay que resaltar que el Perú se ha convertido en el mayor país receptor de solicitantes de asilo venezolanos no solamente en América Latina, sino en el mundo, albergando más del 53\% de todos los solicitantes a nivel global.

\footnotetext{
1 Plataforma regional de coordinación interagencial para refugiados y migrantes de venezuela (2019).

2 Freier (2018) sin paginación.

3 Plataforma regional de coordinación interagencial para refugiados y migrantes de venezuela (2019).
} 


\section{GRÁFICO 1}

Solicitudes de refugio en América Latina, países selectos

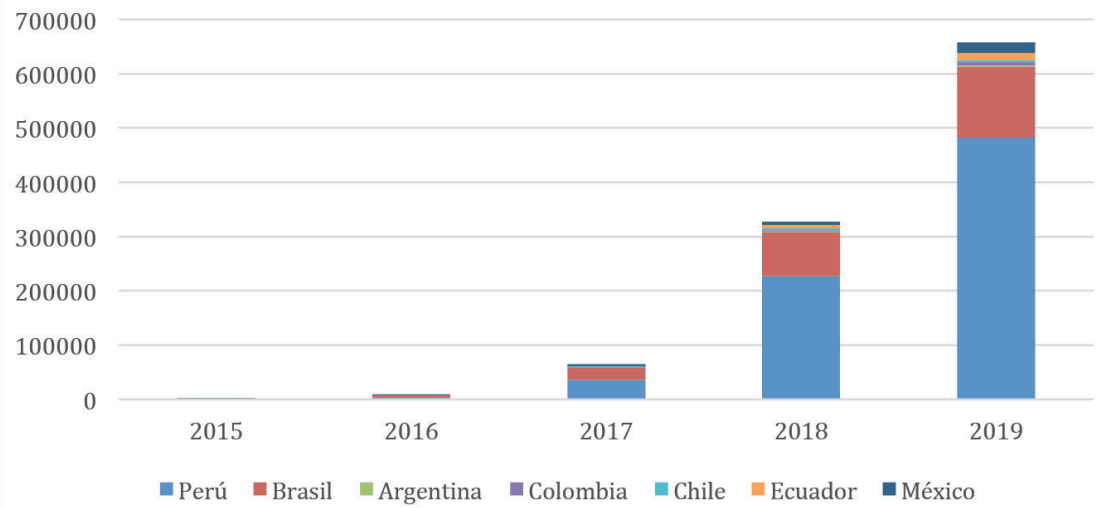

* Registrado hasta diciembre de 2019. Fuente: ACNUR

Aunque los instrumentos internacionales regulaban, por lo menos en teoría, su política de asilo, hasta los años noventa, un número significativo de países de América Latina no tenía formalmente leyes de refugio. En la década de 1990, se inició una reforma en las legislaciones de la mayoría de estados que permitió la promulgación de leyes de refugio más comprensivas y expansivas5. Así, Brasil (1997), Argentina (2006) y México (2011) decretaron nuevas leyes de refugio excepcionalmente expansivas. Por su parte, en el caso de Perú, la Ley del Refugiado, adoptada en 2002, es la primera norma que regula la protección de personas refugiadas acorde a la normativa internacional. Asimismo, las normativas en materia de migración en la mayoría de los países de América Latina se reforman a principios de los 2000 e incorporan un enfoque de derechos humanos ${ }^{6}$.

Es esencial señalar que la mayoría de los países en América Latina han incorporado en esos marcos normativos protectores tanto la definición tradicional de la Convención de Ginebra sobre Refugiados de 1951 como la definición ampliada de la Declaración de Cartagena de 1984. Este marco regional para los refugiados extiende la protección en casos en los que la vida, la seguridad o la libertad sean amenazadas debido a que el país de origen

\footnotetext{
${ }^{4}$ La información recopilada entre los años 2015 y 2018 proviene del portal estadístico del ACNUR, disponible en: http://popstats.unhcr.org/en/overview

Los datos del año 2019, fueron recopilados del Operational Portal: Refugee situations disponible en: https:// data2.unhcr.org/en/situations/vensit

En el caso de Ecuador no hay información oficial disponible para el 2019 mientras que para México ya existe información actualizada hasta marzo del año 2020.

5 Brasil: Ley No 9.474 de 1997; Venezuela: Ley No 37296 de 2001; Guatemala: Acuerdo Gubernamental No 383 de 2001; El Salvador: Decreto No 918 de 2002; Paraguay: Ley No 1938 de 2002; Perú: Ley No 27 891 de 2002; Honduras: Decreto No 208 de 2004; Argentina: Ley No 26165 de 2006; Uruguay: Ley No 18 076 de 2006, Nicaragua: Ley No 655 de 2008; Costa Rica: Ley No 8764 de 2009; Chile: Ley No 20430 de 2010; México: Ley sobre Refugiados y Protección Complementaria’ de 2011; Bolivia: Ley No 251 de 2012; Panamá: Ley No 74 de 2013; Ecuador: Decreto No 1182 de 2012; Colombia: Decreto No 2840 de 2013.

6 Acosta y Freier (2015) p. 8; Ceriani (2018) p. 6.
} 
presente violencia generalizada, agresión extranjera, conflictos internos, violaciones masivas de los derechos humanos u otras situaciones que hayan perturbado seriamente el orden público. Fue sobre todo esa incorporación de la definición de Cartagena que llevó al ACNUR a describir a América Latina como el nuevo líder mundial en protección de refugiados, incluso superando a Europa como modelo de legislación sobre refugiados centrada en los derechos humanos ${ }^{7}$.

La adopción de esos marcos normativos más protectores debe entenderse en el contexto de la reformulación de políticas migratorias frente al rechazo de las políticas de inmigración y refugio de Estados Unidos y la Unión Europea (UE) ante la emigración masiva de ciudadanos latinoamericanos hacia esos destinos desde finales de los años $90 s^{8}$. Asimismo, influyeron otros factores como la redemocratización de la región, la integración regional y la mayor influencia de organizaciones internacionales como la Organización Internacional para las Migraciones (OIM) y el ACNUR.

Sin embargo, estos avances a nivel normativo no han sido exentos de obstáculos y retrocesos ${ }^{9}$. Por un lado, se ha llevado a cabo reformas regresivas de leyes migratorias en algunos países de la región ${ }^{10}$. Además, algunos países no cuentan hasta la fecha con un marco normativo integral en materia migratoria ${ }^{11}$. Por otro lado, se ha observado en la región giros restrictivos con la adopción de visas a la población venezolana, por ejemplo, en Ecuador y Perú ${ }^{12}$ así como el endurecimiento de las políticas migratorias, mediante otras medidas, la militarización de las fronteras en el caso mexicano ${ }^{13}$.

También es muy importante destacar que, a comienzos del siglo XXI, América Latina y el Caribe acogieron relativamente pocos refugiados y solicitantes de asilo. Por lo tanto, el actual éxodo de ciudadanos venezolanos y el incremento rápido de solicitudes de asilo por parte de ciudadanos venezolanos es una situación nueva. Si bien la Comisión Interamericana de Derechos Humanos ya en 2018 caracteriza a la migración venezolana como forzada y llama los Estados a aplicar además de la definición tradicional de refugiado la definición ampliada de Cartagena ${ }^{14}$, la mayoría de los Estados no ha optado por aplicar esta definición ${ }^{15}$. Por el contrario, frente a esta migración los países de la región, en vez de optar por aplicar la definición de Cartagena y así ofrecer un marco de protección amplia, han op-

\footnotetext{
7 Freier (2015) p. 119.

8 Acosta y Freier (2015) p. 9.

9 Para un análisis completo desde el ámbito de las legislaciones migratorias ver Ceriani (2018) p. 6-10.

10 Nos referimos por ejemplo al caso de Argentina con la modificación de la Ley de Migraciones por el Decreto $70 / 2017$

11 Nos referimos en especial a los casos de Colombia, por no contar con un marco normativo integral en materia migratoria y Chile, por no haber reformado su ley migratoria adoptada durante la dictadura.

12 Freier y Luzes (2020) sin paginación; Amnistía Internacional (2020) p. 18.

13 Ceriani (2018) p. 10.

14 CIDH 2018. En el mismo sentido véase la nota orientativa del ACNUR: https://www.refworld.org.es/ docid/5ce2d44c4.html

15 México lo ha aplicado mediante un procedimiento individual mientras que Brasil ha reconocido en diciembre 2019 mediante un procedimiento prima facie la condición de refugiado a más de 20,000 venezolanos y venezolanas. Para el caso de Brasil ver: Acosta y MAdrid (2020) pp. 4-8.
} 
tado por desarrollar mecanismos temporales, ad hoc, excepcionales y discrecionales ${ }^{16}$. Ello no solo se explica por motivos puramente jurídicos, sino que dependiendo de los Gobiernos y sus posicionamientos hacia Venezuela se reconocen las personas venezolanas como refugiadas o como migrantes económicos ${ }^{17}$. Más allá de estos cuestionamientos políticos, frente al incipiente debate legal ${ }^{18}$ que existe alrededor de esta definición y sus contornos es necesario entender la definición de Cartagena en su dimensión jurídica y dentro del procedimiento de determinación de la condición de refugiado.

En ese marco, este artículo propone explorar la definición de Cartagena desde sus orígenes hasta su posible aplicación en un caso concreto, el del desplazamiento de personas venezolanas a la región latinoamericana. Para ello, el artículo se estructura en cuatro apartados que profundizan sobre la definición ampliada de Cartagena y, en especial, sobre el elemento situacional de violación masiva de derechos humanos y su aplicación al caso venezolano. El foco sobre este elemento situacional se explica por tres razones principales. La primera está vinculada con la incorporación de este elemento situacional en todas las legislaciones de América Latina excepto Belice. La segunda se debe a la necesidad de entender el concepto de violación masiva y sus vínculos con otra terminología tales como las violaciones graves de derechos humanos definidas en el Derecho Internacional de los Derechos Humanos. Por último, existe un consenso entre los países de la región y los organismos internacionales en reconocer las graves violaciones de derechos humanos en Venezuela.

En el primer apartado del artículo, se revisará la Declaración de Cartagena y sus aportes para la protección de personas refugiadas con el objetivo de entender el espíritu de esta definición ampliada. En segundo lugar, se desarrollará un acápite sobre los procedimientos de determinación de la condición de refugiado incluyendo el reconocimiento prima facie.

En el tercer acápite, partiendo de la ausencia de una definición jurídica del supuesto de "violación masiva de derechos humanos" contenido en la Declaración de Cartagena, se propondrá un marco conceptual propio a partir de distintas fuentes, tales como jurisprudencia de la Corte Interamericana de Derechos Humanos y doctrina. Finalmente, en el cuarto acápite, se aplicará el marco conceptual al caso concreto de Venezuela.

\section{LA DECLARACIÓN DE CARTAGENA Y SUS APORTES}

El primer instrumento internacional que contempla la definición de refugiado es la Convención sobre el Estatuto de los Refugiados (en adelante Convención de 1951), modificada por el Protocolo sobre el Estatuto de los Refugiados de $1967^{19}$. Según el artículo

\footnotetext{
16 Acosta, Blouin y Freier (2019) p. 8.

17 Acosta y Madrid (2020) p. 8.

18 Sobre la definición de Cartagena desde un punto de vista jurídico resalta el trabajo de Mondelli 2018.

19 El Protocolo de 1967 es un instrumento independiente de la Convención de 1951. El aporte fundamental del Protocolo es que anula los límites geográficos y temporales contenidos en la Convención de 1951. En efecto, la Convención limitaba el reconocimiento de la condición de refugiado a las personas que se encontraban fuera de su país de origen debido a acontecimientos ocurridos antes del 1 de enero de 1951 y dejaba la posibilidad a los Estados de limitar la protección a las personas que hubieran llegado de Europa. Estas dos limitaciones no tomaban en cuenta las numerosas nuevas situaciones de refugio en diferentes lugares del mundo y es así que se aprobó este Protocolo.
} 
$1^{\circ}$ de dicho instrumento, la persona refugiada es quien: "debido a fundados temores de ser perseguida por motivos de raza, religión, nacionalidad, pertenencia a determinado grupo social u opiniones políticas, se encuentre fuera del país de su nacionalidad y no pueda o, a causa de dichos temores, no quiera acogerse a la protección de tal país; o que, careciendo de nacionalidad y hallándose, a consecuencia de tales acontecimientos, fuera del país donde antes tuviera su residencia habitual, no pueda o, a causa de dichos temores, no quiera regresar a él”20. Sin embargo, con el trascurrir de los años, algunos Estados observaron que esta definición excluía a diversos flujos de movilidad forzada. Por ello, surgieron las definiciones regionales ampliadas ${ }^{21}$, que buscaron "proporcionar protección a las personas refugiadas en situaciones humanitarias específicas, incluidas las llegadas a gran escala de personas que huyen de situaciones o circunstancias específicas en su país de origen"22.

En Latinoamérica, en un contexto de desplazamiento masivo de personas en los años ochenta, cuando más de dos millones de personas fueron desplazadas por las guerras civiles en El Salvador, Guatemala y Nicaragua y buscaron refugio en México, Panamá y Estados Unidos, se buscó una respuesta regional que pueda ampliar el concepto de refugiado ${ }^{23}$.

Es así que se produjo el Coloquio sobre la Protección Internacional de los Refugiados en América Central, México y Panamá en Cartagena en noviembre de 1984. En este evento, los Estados reconocieron que la Convención de 1951 y su Protocolo de 1967 no abordaban la situación de estos desplazados centroamericanos de manera adecuada ${ }^{24}$. Ante esta situación, adoptaron la Declaración de Cartagena, en la cual se establece que:

"la definición o concepto de refugiado recomendable para su utilización en la región es aquella que además de contener los elementos de la Convención de 1951 y el Protocolo de 1967, considere también como refugiados a las personas que han huido de sus países porque su vida, seguridad o libertad han sido amenazadas por la violencia generalizada, la agresión extranjera, los conflictos internos, la violación masiva de los derechos humanos u otras circunstancias que hayan perturbado gravemente el orden público" (resaltado nuestro) ${ }^{25}$.

La Declaración de Cartagena surge como un instrumento regional no vinculante. Sin embargo, de acuerdo con Mondelli, la definición regional tiene el carácter de una norma consuetudinaria y, por lo tanto, de obligatorio cumplimiento, ya que cuenta con los requisitos de tal; es decir, el uso de esta definición existe como una práctica general y es aceptada como derecho (opinio iuris) ${ }^{26}$.

\footnotetext{
20 Protocolo de sobre el Estatuto de los Refugiados de 1967, art. 1.

21 En el continente africano, la Convención de la Organización de la Unidad Africana (OUA) también propone una definición ampliada en su artículo 1.2: "El término refugiado se aplicará también a toda persona que, a causa de una agresión exterior, una ocupación o una dominación extranjera, o de acontecimientos que perturben gravemente el orden público en una parte o en la totalidad de su país de origen, o del país de su nacionalidad, está obligada a abandonar su residencia habitual para buscar refugio en otro lugar fuera de su país de origen o del país de su nacionalidad".

22 Alto Comisionado de las Naciones Unidas para los Refugiados (2016) p. 2.

23 Berganza (2016) pp. 46-47.

24 Arboleda (1991) p. 186.

25 Declaración de Cartagena (1984) p. 3.

26 Mondelli (2018) p. 95.
} 
Por otro lado, el objetivo de la definición ampliada no es eliminar o sustituir la definición tradicional de la condición de refugiado, sino más bien complementarla para extender la protección a las personas, basándose en causas objetivas vinculadas al país o región de origen. Además, si bien es un instrumento regional, se aplica al conjunto de personas, sin importar su nacionalidad, que requieren protección internacional en la región latinoamericana. Asimismo, es interesante observar cómo esta definición incluye y relaciona las diferentes ramas del Derecho Internacional, entre ellas el Derecho Internacional de los Derechos Humanos, ya que contribuye "a ampliar la aplicación de las normas de derechos humanos a la solución de los problemas de los refugiados al reconocer las violaciones masivas de los derechos humanos como una causa importante de migración forzada"27 (traducción propia).

En palabras de Murillo, la Declaración de Cartagena sobre refugiados de 1984 es "un verdadero Manual de Derecho Internacional de Refugiados, basado en la Convención sobre el Estatuto de los Refugiados de 1951 y su Protocolo de 1967, que recoge la generosa tradición de asilo de Latinoamérica y se ve complementado por la integración de las normas y estándares de protección de Derechos Humanos, en particular la Convención Americana de Derechos Humanos"28.

Por lo tanto, la definición ampliada que propone la Declaración de Cartagena tiene como objetivo principal proporcionar protección frente a riesgos situacionales o grupales. Para evaluar las solicitudes de reconocimiento de refugio y poder aplicar esta definición, hay que examinar la situación en el país de origen y la situación particular del solicitante, además de la exposición de la persona o de un grupo de personas a los riesgos inherentes a las situaciones mencionadas ${ }^{29}$. Sin embargo, hay que tener en cuenta que en este caso el riesgo a evaluar se refiere más al aspecto espacial y temporal, no tanto a los "fundados temores de ser perseguido" individualmente como lo establece la Convención de 1951. Esto conlleva diversas consecuencias. La primera es que, en la aplicación de Cartagena, lo fundamental no son las circunstancias personales del sujeto concreto, sino la situación en la que se encuentra el país que ha abandonado. Son circunstancias "objetivamente" más identificables ${ }^{30}$.

Lo segundo es que la definición de Cartagena se refiere a "amenaza a la vida, la seguridad o la libertad", por lo que se deduce que el daño no se ha tenido obligatoriamente que materializar, sino que debe existir un riesgo, una posibilidad de que suceda. Este hecho es el que justificaría la necesidad de protección internacional. Además, dentro de esta definición también se pueden incluir consecuencias indirectas que estas situaciones puedan conllevar, tales como pobreza, enfermedades, violencia, desnutrición, etc.

Finalmente, el riesgo o peligro no debe ser necesariamente individual, sino que puede afectar a una colectividad. Por este mismo motivo, si las autoridades de un país evalúan que las personas llegadas de un determinado país pueden ser reconocidas como refugiadas en el marco de esta definición ampliada, debería ser aplicada coherentemente a otras personas que huyen del mismo país (o área/región dentro de un país) en circunstancias similares.

27 Cuéllar et al. (1991) p. 491.

28 Murillo (2004). Sin paginación.

29 Alto Comisionado de las Naciones Unidas para los Refugiados (2013) p. 3.

30 Alto Comisionado de las Naciones Unidas para los Refugiados (2016) p. 11. 
Por lo tanto, sería una definición que surge con el espíritu de ser aplicada de manera "masiva", no solo individualmente ${ }^{31}$.

\section{EL PROCEDIMIENTO DEL RECONOCIMIENTO DE LA CONDICIÓN DE REFUGIADO: CONSIDERACIONES GENERALES Y PRIMA FACIE}

Tal como afirman Goodwin-Gill y McAdam para una efectiva implementación de la Convención de 1951 y su protocolo, es necesario un procedimiento interno de reconocimiento de la condición de refugiado ${ }^{32}$. El Manual del ACNUR considera que "es evidente que, para que los Estados partes en la Convención y en el Protocolo puedan aplicar sus disposiciones, es necesario que los refugiados sean identificados. Esa identificación, es decir, la determinación de la condición de refugiado, aunque se menciona en la Convención de 1951 (artículo 9), no está regulada expresamente" ${ }^{33}$. En efecto, ningún instrumento del Derecho Internacional de los Refugiados, es decir ni la Convención ni el Protocolo ni tampoco los instrumentos regionales ${ }^{34}$, establece cómo se debe llevar a cabo el procedimiento de determinación de la condición de refugiado ${ }^{35}$.

Siguiendo este orden de ideas, el procedimiento para determinar el estatuto o la condición de refugiado puede ser definido como:"(el) acto o mecanismo por medio del cual una autoridad competente evalúa las condiciones particulares de un individuo -que reclama ser un refugiado- con el objetivo de establecer si él efectivamente califica como tal. Es un acto legal o mecanismo sobrecargado de una gran responsabilidad de carácter humanitario, debido al impacto que tiene sobre el destino individual" (resaltado nuestro) ${ }^{36}$. Además, la existencia misma de procedimientos para la determinación de la condición de refugiado garantiza una serie de derechos previstos en los instrumentos del Derecho Internacional de los Refugiados y, en especial, la no devolución (non-refoulement) prevista por el artículo 33 de la Convención ${ }^{37}$.

En cuanto a los tipos de procedimientos que se pueden establecer, de acuerdo al ACNUR, "cada Estado contratante puede establecer el procedimiento que estime más apropiado, habida cuenta de su propia estructura constitucional y administrativa" 38 . Pero, si bien los Estados pueden definir el procedimiento, este debe cumplir con una serie de estándares que el ACNUR ha desarrollado ${ }^{39}$.

31 Alto Comisionado de las Naciones Unidas para los Refugiados (2013) p. 6; Arboleda (1991) p. 199.

32 Goodwin-Gill y McAdam (2007) p. 530.

33 Alto Comisionado de las Naciones Unidas para los Refugiados (1992). Apartado 189.

34 Con instrumentos regionales nos referimos a la Declaración de Cartagena y a la Convención de la Organización de la Unidad Africana (OUA).

35 Galindo (2001) p. 94.

36 FisChel (2001) p. 104.

37 FisCHel (2001) p. 104.

38 Alto Comisionado de las Naciones Unidas para los Refugiados (1992) apartado 189.

39 Se establecen garantías relacionadas al acceso al territorio mediante el derecho a la no devolución y las garantías del debido proceso. Alto Comisionado de las Naciones Unidas para los Refugiados (1992) apartados 189 y 192. La Corte Interamericana de Derechos Humanos ha desarrollado estos estándares. Ver en particular el caso Pacheco Tineo contra Bolivia (2013). 
De acuerdo con Lettieri, los procedimientos de determinación de la condición de refugiado tienen determinadas características específicas. Una de ellas es que cada Estado define el procedimiento con una cierta discrecionalidad, por lo que estos procedimientos aparecen "a medio camino entre el Derecho Internacional y las distintas áreas del derecho interno. De allí que a veces resulte difícil, por ejemplo, compatibilizar las exigencias del derecho internacional de refugiados con las prescripciones del derecho administrativo de un Estado" ${ }^{40}$. Ello puede también explicar que en la práctica los porcentajes de aceptación de solicitudes de reconocimiento varían mucho de un país a otro, aún dentro de la misma región ${ }^{41}$. Asimismo, es importante recordar que la información disponible sobre los países de origen usada por los oficiales de elegibilidad es rara vez neutral y objetiva. La influencia de los medios de comunicación u otros elementos culturales o históricos a la hora de evaluar las peticiones tampoco debe ser pedida de vista ${ }^{42}$. Por otra parte, la ausencia de un procedimiento establecido a nivel internacional puede generar que "debido a estas diferencias en los enfoques [de los procedimientos de reconocimiento de la condición de refugiado], algunas solicitudes de la condición de refugiado permanecen pendientes, lo que provoca que algunos refugiados no puedan recibir protección garantizada por el Derecho Internacional” ${ }^{33}$.

En el contexto suramericano, estos procedimientos se han caracterizado por una gran opacidad. Partiendo del principio de confidencialidad aplicado en los procedimientos de reconocimiento y excediendo este objetivo, los Estados no han permitido que las decisiones puedan ser revisadas por los propios refugiados, las organizaciones de sociedad civil, las instituciones internacionales o la academia ${ }^{44}$.

Adicionalmente al procedimiento regular del reconocimiento de la condición de refugiado, existe la posibilidad de reconocer refugiados prima facie. El concepto prima facie no se ha definido en ningún instrumento del Derecho Internacional de los Refugiados (DIR) pero sí se ha identificado como una práctica por parte de los Estados ${ }^{45}$. Para Albert, este reconocimiento, cuyo uso será decisión de cada Estado, se presenta cuando un Estado de acogida (A) reconoce la condición de refugiado de todos los individuos de otro Estado (B) que ingresaron a su jurisdicción durante cierto periodo de tiempo $(\mathrm{C})$, basándose para ello en "información objetiva" conocida por el Estado A sobre las condiciones de vida en el Estado B durante el periodo de tiempo C. En esta línea, para ser reconocido como refugiado, bastará que la persona demuestre que su Estado de origen es B y que huyó durante el periodo de tiempo C para que el Estado A considere acreditados todos los elementos de la definición de refugiado y le reconozca tal condición. La decisión de usar un reconocimiento prima facie ocurre cuando el Estado receptor ve su capacidad superada para responder a las solicitudes con el procedimiento regular de determinación de la condición de refugiado

\footnotetext{
40 LetTieri (2012) pp. 110-111.

41 FisCHel (2001) p. 219.

42 Durieux (2008) p. 153.

43 Hossain Bhuiyan (2013) p. 67.

44 LETTIERI (2012) p. 110-111.

45 ACNUR (2015) p. 2.
} 
$y$, en ese sentido, no tiene que ver con el número de personas solicitantes sino con la capacidad del sistema de asilo en responder a las solicitudes ${ }^{46}$.

En cuanto al procedimiento, la principal diferencia con el procedimiento regular es el hecho de que este reconocimiento se basa de manera más sustancial en la información objetiva de la situación del país que en la situación personal del solicitante. Ello es fácilmente entendible a la luz de la definición planteada: si la persona ha salido del Estado B durante el tiempo C, es refugiado a primera vista, debido a la situación de su país de origen $^{47}$. En cuanto a las consecuencias jurídicas del reconocimiento prima facie es necesario hacer énfasis en el hecho de que son las mismas que en el caso del procedimiento regular. Es decir, la persona que sea reconocida como refugiada prima facie tendrá garantizados los mismos derechos que aquellas que son reconocidas por la vía habitual. ${ }^{48}$ Otro tema de particular interés es la discusión entre reconocimiento individual o grupal. Si bien el ACNUR los identifica como dos mecanismos distintos, varios autores analizan los límites borrosos en la práctica de los Estados entre los reconocimientos individuales y grupales.

El reconocimiento prima facie se puede hacer mediante casos individualizados o casos grupales ${ }^{49}$. El concepto prima facie, tal como lo afirman Cantor y Trimiño Mora, es especialmente relevante para la definición ampliada de Cartagena que por esencia se refiere a grupos identificables de personas desplazadas por la situación de su país de origen. En ese sentido esta definición ampliada “(...) parece tener la intención de facilitar el reconocimiento prima facie del estatuto de refugiado cuando no pueda llevarse cabo la determinación individual por razones prácticas" ${ }^{\circ}$. Es así que si bien hasta ahora el reconocimiento prima facie se ha aplicado principalmente en el contexto de la definición ampliada africana, queda claro que se puede aplicar con todas las definiciones de refugiados y, en especial, en el contexto de las definiciones ampliadas ${ }^{51}$.

Habiendo aclarado la naturaleza y los retos del procedimiento del reconocimiento de la condición de refugiado regular y prima facie, toca ahora analizar el elemento situación de violación masiva de los derechos humanos previsto en la definición ampliada de Cartagena.

\section{UN ACERCAMIENTO AL ELEMENTO SITUACIONAL DE “VIOLACIÓN MASIVA DE LOS DERECHOS HUMANOS"}

Los elementos situacionales de la definición de Cartagena han sido objeto de varias interpretaciones. Por un lado, está la interpretación "convencional", que busca entender los conceptos como si hubieran sido planteados en un tratado. Por otra parte, se encuentra una interpretación más flexible, que propone que estos conceptos no sean interpretados de forma muy legalista o literal ${ }^{52}$. De acuerdo a Cantor y Trimiño, la primera postura es

\footnotetext{
46 Albert (2010) p. 65-66; Acnur (2015) p. 4.

47 Albert (2010) pp. 70-71.

48 ACNur (2015) p. 3; Albert (2010) p. 71.

49 Durieux (2008) p. 160; Albert (2010) pp. 82-83.

50 Cantor y Trimiño (2015) pp. 184-185.

51 Durieux (2008) p. 152.

52 Cantor y Trimiño (2015) pp. 177-179.
} 
problemática ya que parte de la hipótesis de que las declaraciones son igual de precisas que los tratados y que, además, usan conceptos reconocidos en el Derecho Internacional. Lejos de ser este el caso, la terminología usada en las diversas definiciones ampliadas de refugiados no son categorías jurídicas existentes y, en ese sentido, la Declaración de Cartagena no plantea conceptos del Derecho Internacional ${ }^{53}$. Por ello, si se desea lograr una mejor compresión del concepto de refugiado planteado en este documento, el enfoque interpretativo debe partir del objetivo y del contexto en el que se elaboró la mencionada Declaración ${ }^{54}$.

Además, teniendo en cuenta los grandes retos que existen en los sistemas de asilo de la región y, en especial, en lo relativo a la formación de los tomadores de decisiones en los procesos de reconocimiento de refugio ${ }^{55}$, la cuestión de la delimitación de los conceptos presentados en la definición de Cartagena no es menor. En ese sentido, para el presente artículo, se busca definir qué situaciones podrían ser consideradas violaciones masivas de los derechos humanos sin perder de vista una mirada más integral y flexible desde el espíritu de la Declaración de Cartagena.

En cuanto al elemento situacional de violación masiva de derechos humanos, como se mencionaba, es importante resaltar que no existe ningún instrumento del Derecho Internacional que lo defina. Este concepto se relaciona con violaciones graves, flagrantes y extremas de derechos humanos ${ }^{56}$. Incluso, los diversos órganos surgidos a partir de tratados internacionales y los diferentes tribunales utilizan dichos conceptos de manera indiscriminada, lo que dificulta su concreción ${ }^{57}$.

En el ámbito de las Naciones Unidas, es en 1967 cuando por primera vez se utilizó el término violaciones notorias o flagrantes (en inglés, gross violations) de derechos humanos ${ }^{58}$. Sin embargo, no se llegó a establecer una definición. Años después, el Documento de Trabajo presentado ante la Subcomisión de Prevención de Discriminaciones y Protección a las Minorías de la Comisión de Derechos Humanos de las Naciones Unidas por el Sr. Stanislav Chernichenko ${ }^{59}$, explica que diferenciar entre violaciones manifiestas de derechos humanos y violaciones menos graves es difícil y no puede ser del todo precisa. Chernichenko plantea que el genocidio, las desapariciones y actos similares son violaciones masivas y que, aunque la tortura o la detención arbitraria o prolongada pueden ser violaciones individuales, en la práctica, si quedan impunes, suelen constituirse como prácticas reiteradas o sistemáticas, lo cual las convierte en violación masiva. Como se puede observar, las diferencias entre los distintos conceptos son borrosas. Sin embargo, se entiende que hay dos acercamientos posibles: por el tipo de derecho vulnerado o por la magnitud de la violación.

\footnotetext{
53 Arboleada (1991) p. 204.

54 Cantor y Trimiño (2015) p. 179.

55 Cantor y Trimiño (2015) p. 175.

56 Geneva Academy (2014) p. 13. Usamos la traducción propuesta en el texto de las palabras en inglés Gross; Flagrant; Grave; Serious; Grave; Flagrant; Extreme; Egregious; Severe; Very serious; Particularly grave; Particularly serious; Gravest; Most serious.

57 Geneva ACAdemy (2014) pp. 19, 34-35.

58 Comisión de Derechos Humanos de la ONU (1967) y Consejo Económico y Social de la OrganizaCión de las Naciones Unidas (1967).

59 Chernichenko (1993) p. 12.
} 
Por otro lado, existe una clara relación de mutua influencia entre el concepto de grave violación de derechos humanos y crímenes contra la humanidad ${ }^{60}$. El crimen de lesa humanidad "se comet[e] como parte de un ataque generalizado o sistemático contra una población civil y con conocimiento de dicho ataque"61; es decir, en un determinado contexto. Asimismo, "[s]egún el corpus iuris del Derecho Internacional, un crimen de lesa humanidad es en sí mismo una grave violación a los derechos humanos y afecta a la humanidad toda"62. De este modo, siempre que se haga referencia a crímenes de lesa humanidad se hablará también de graves violaciones de derechos humanos.

De acuerdo a la doctrina, existe un consenso en cuanto a una lista de derechos que, de ser vulnerados, se constituyen violaciones graves (ver cuadro 1). Sin embargo, una lista enumerativa es problemática en sí, teniendo en cuenta la evolución de los derechos humanos ${ }^{63}$.

Con la finalidad de un mayor acercamiento al elemento situacional analizado, es importante recurrir a las sentencias y desarrollos jurisprudenciales sobre estos términos ${ }^{64}$. Para el propósito de este artículo, solo se hará referencia al Sistema Interamericano de Derechos Humanos (SIDH) por su especial relevancia en la región, y su influencia en la mención a "violación masiva" y en el desarrollo de los conceptos ${ }^{65}$. En el ámbito del SIDH, se ha usado los términos grave y serio para calificar violaciones de derechos humanos de manera intercambiable ${ }^{66}$.

La Corte Interamericana de Derechos Humanos (Corte IDH) ha señalado que las graves violaciones pueden ser "la tortura, las ejecuciones sumarias, extralegales o arbitrarias y las desapariciones forzadas, todas ellas prohibidas por contravenir derechos inderogables reconocidos por el Derecho Internacional de los Derechos Humanos" ${ }^{67}$. Como se puede observar, la Corte construye un vínculo entre el carácter de inderogabilidad de los dere$\operatorname{chos}^{68}$ y su carácter de grave violación ${ }^{69}$. En cuanto al carácter masivo, debe analizarse la escala o magnitud de la violación ${ }^{70}$. Otro indicador importante puede ser la imposición de las medidas provisionales ordenadas por la Corte IDH o cautelares por parte de la Comisión

\footnotetext{
60 Geneva Academy (2014) p. 8.

61 Art. 7 del Estatuto de Roma.

${ }^{62}$ Corte Interamericana de Derechos Humanos (2006) párr. 105.

63 Geneva Academy (2014) p. 19.

${ }^{64}$ Para otro análisis, ver LIWANGA, Roger-Claude. The meaning of "gross violation" of human rights: a focus on international tribunals' decisions over the DRC conflicts; Democratic Republic of the Congo Denver Journal of International Law and Policy.

65 Geneva Academy (2014) p. 23; Cantor y Trimiño (2015) p. 169; Lyra et al. (2016) p. 220.

66 Geneva Academy (2014) p. 24.

67 Corte Interamericana de Derechos Humanos (2001) párr. 41.

68 De acuerdo al artículo 27.2, los derechos inderogables en caso de guerra, de peligro público o de otra emergencia que amenace la independencia o seguridad del Estado parte son "3 (Derecho al Reconocimiento de la Personalidad Jurídica); 4 (Derecho a la Vida); 5 (Derecho a la Integridad Personal); 6 (Prohibición de la Esclavitud y Servidumbre); 9 (Principio de Legalidad y de Retroactividad); 12 (Libertad de Conciencia y de Religión); 17 (Protección a la Familia); 18 (Derecho al Nombre); 19 (Derechos del Niño); 20 (Derecho a la Nacionalidad), y 23 (Derechos Políticos), ni de las garantías judiciales indispensables para la protección de tales derechos".

69 Corte Interamericana de Derechos Humanos (2006) párr. 160, entre otros.

70 Corte Interamericana de Derechos Humanos (2009a) párr. 152.
} 
Interamericana de Derechos Humanos $(\mathrm{CIDH})^{71}$. Sin embargo, no existe un criterio claro en el caso de la Corte IDH: en algunas ocasiones, solamente la naturaleza del derecho será suficiente para determinar su carácter de gravedad $^{72}$; en otros casos, la escala y magnitud serán consideradas imprescindibles ${ }^{73}$; y, en otros, el tipo de víctima y su vulnerabilidad ${ }^{74}$. En algunos casos, la combinación de estos factores será necesaria para la determinación de la grave violación ${ }^{75}$.

En el contexto de la definición ampliada de Cartagena, es necesario referirse a la Conferencia Internacional Sobre Refugiados Centroamericanos (CIREFCA), que reunió a expertos del Sistema Interamericano de Derechos Humanos para plantear pautas de orientación sobre la Declaración de Cartagena ${ }^{76}$. Los expertos concluyeron que la violación masiva de derechos humanos ocurre cuando "se producen violaciones en gran escala que afectan los derechos humanos y las libertades fundamentales consagradas en la Declaración Universal de Derechos Humanos y otros instrumentos relevantes. En particular, pueden considerarse como violaciones masivas de Derechos Humanos, la negación de los derechos civiles, políticos, económicos, sociales y en una forma grave y sistemática así como aquellas que son objeto de la Resolución 1503" (resaltado nuestro) ${ }^{77}$. Es interesante que se abarquen no solamente las violaciones de derechos civiles y políticos, sino también las de derechos económicos y sociales. Adicionalmente, esta definición relaciona el concepto de violación masiva de derechos humanos con los conceptos de violaciones graves y sistemáticas. Fortin, por su lado, identifica dos posibilidades para la aplicación del elemento situacional de violación masiva de los derechos humanos previsto en la definición ampliada: i) se han presentado un extenso número de violaciones de derechos humanos, y ii) las violaciones son de naturaleza particularmente seria ${ }^{78}$. El ACNUR, por otro lado, ha comentado que esta definición opera cuando las consecuencias de estas violaciones recaen sobre grandes grupos de población o incluso sobre la sociedad en su conjunto ${ }^{79}$.

\footnotetext{
71 Reglamento de la Comisión Interamericana de Derechos Humanos. Art. 25.

72 Corte Interamericana de Derechos Humanos (2009b).

73 Corte Interamericana de Derechos Humanos (2013).

74 Corte Interamericana de Derechos Humanos (1999).

75 Geneva ACademy (2014) p. 25.

76 Cantor y Trimiño (2015) p. 172.

77 Grupo de Expertos para la Conferencia Internacional sobre Refugiados Centroamericanos (1989) p. 11. La resolución 1503 fue adoptada en 1970 por el Consejo Económico y Social (Ecosoc) de la Organización de las Naciones Unidas, que estableció un procedimiento en virtud del cual un grupo de trabajo de la Subcomisión podría, de manera confidencial, examinar las comunicaciones "que parecen revelar un patrón consistente de violaciones graves y certificadas de los derechos humanos y las libertades fundamentales".

78 Fortin (2005) p. 294.

79 Alto Comisionado de las Naciones Unidas para los Refugiados (2016) p. 15.
} 
CUADRO 1

Lista de las violaciones de derechos humanos consideradas graves

\begin{tabular}{|c|}
\hline Genocidio \\
\hline Asesinatos arbitrarios o sumarios \\
\hline Desapariciones \\
\hline Esclavitud \\
\hline Prolongada y detención arbitraria \\
\hline Tortura y Tratos inhumanos y crueles \\
\hline Crímenes contra la humanidad \\
\hline Apartheid \\
\hline
\end{tabular}

Elaboración propia a partir de Damrosh Lori F 2015.

En base a lo anterior, se ha elaborado un cuadro propio que permite establecer las dimensiones para aproximarnos a la violación masiva de derechos humanos. El cuadro retoma los dos acercamientos de la definición: la lista enumerativa basada en la gravedad de la violación y las características de la violación que la convierten en masiva. En este sentido, además de la lista consensuada de derechos, para el caso de análisis del presente artículo, se debe agregar los derechos económicos, sociales y culturales (DESC). Ello, teniendo en cuenta el espíritu de Cartagena y los avances recientes en materia de exigibilidad de DESC ${ }^{80}$. En cuanto al carácter masivo de las violaciones, ello está relacionado a dos aspectos. Por un lado, el que dichas violaciones sean sistemáticas, es decir, que sigan o se ajusten a un patrón estructural. Por otro lado, es necesario evaluar la magnitud de estas vulneraciones de derechos, de tal manera que afecten a una colectividad o a un grupo amplio de población.

En suma, tanto la lista enumerativa como las características de la violación son indicios de una violación masiva de derechos humanos y ofrecen una mirada complementaria. Teniendo en cuenta ello, a continuación, se aplica este marco conceptual a la situación de Venezuela.

\footnotetext{
80 Corte Interamericana de Derechos Humanos (2017). Para un análisis de la exigibilidad de los DeSC revisar: ANTKOWIAK (2015) pp. 259-276; INTERSENTI y ABRAMOVICH (2007) pp. 34-53.
} 
Revista Chilena de Derecho, vol. 47 No 2, pp. 385 - 410 [2020]

Berganza Setién, Isabel / Blouin, Cécile / Freier, Luisa Feline "El elemento situacional de violación masiva de derechos..."

\section{CUADRO 2}

Aproximación al concepto de violación masiva de derechos humanos en el contexto de la definición ampliada de Cartagena

\begin{tabular}{|c|c|}
\hline Lista enumerativa de derechos violados & Características de la violación \\
\hline Crímenes de lesa humanidad & \multirow{4}{*}{$\begin{array}{c}\text { Sistemática } \\
\text { (siguen o se ajustan a un sistema) }\end{array}$} \\
\hline Tortura y tratos inhumanos y crueles & \\
\hline Asesinatos arbitrarios & \\
\hline Detenciones arbitrarias & \\
\hline Esclavitud, servidumbre y trata de seres humanos & \multirow{4}{*}{$\begin{array}{l}\text { Magnitud } \\
\text { (afecten a una colectividad o a un } \\
\text { grupo amplio de población) }\end{array}$} \\
\hline Ejecuciones sumarias, extralegales o arbitrarias & \\
\hline Desapariciones forzadas & \\
\hline DESC & \\
\hline
\end{tabular}

Elaboración propia.

\section{EL ELEMENTO SITUACIONAL DE "VIOLACIÓN MASIVA DE LOS DERECHOS HUMANOS" EN EL CASO VENEZOLANO}

En este acápite, se parte de la aproximación realizada en el apartado anterior a los elementos o situaciones que permiten afirmar que existe una "violación masiva de los derechos humanos" en un determinado país, para analizar la situación concreta que vive Venezuela. Ello se realizará a través del estudio de diversos informes y declaraciones elaborados por organismos supranacionales y por diversos Estados de manera conjunta. Los documentos a analizar (Cuadro No 3) se han escogido en base a dos criterios:

1. Diversidad de fuentes. De esta manera, se analiza un informe de las Naciones Unidas, dos de la Organización de Estados Americanos y otro de la Comisión Interamericana de Derechos Humanos. Además, se hace mención a las Declaraciones realizadas por el Grupo de Lima ${ }^{81}$, debido a la importancia que ha tenido dicho grupo a la hora de realizar un posicionamiento político respecto a la situación que vive Venezuela.

2. Año de elaboración. Se ha buscado que sean documentos que correspondan a los años de mayor desplazamiento de la población venezolana. Por ello los informes y declaraciones seleccionados empiezan en 2017. Adicionalmente, se ha seleccionado los más recientes posibles para recoger la situación actual.

81 El Grupo de Lima se estableció tras la firma de la Declaración de Lima el 8 de agosto de 2017. Está conformado por los doce países que inicialmente firmaron la declaración (Argentina, Brasil, Canadá, Chile, Colombia, Costa Rica, Guatemala, Honduras, México, Panamá, Paraguay y Perú), más Guyana y Santa Lucía que se unieron posteriormente. 


\section{CUADRO No 3}

Informes sobre la situación de Venezuela que han sido analizados

\begin{tabular}{|c|c|c|}
\hline Nombre & Organismo & Fecha \\
\hline $\begin{array}{l}\text { Informe de la Alta Comisionada de las } \\
\text { Naciones Unidas para los Derechos } \\
\text { Humanos sobre la Situación de los } \\
\text { Derechos Humanos en la República } \\
\text { Bolivariana de Venezuela. A/HRC/41/18 }\end{array}$ & $\begin{array}{l}\text { Consejo de Derechos } \\
\text { Humanos de las } \\
\text { Naciones Unidas }\end{array}$ & 4 de julio de 2019 \\
\hline $\begin{array}{c}\text { Informe del Grupo de Trabajo de la OEA } \\
\text { para abordar la crisis de migrantes y } \\
\text { refugiados venezolanos en la Región. } \\
\text { OEA/Ser.D/XV.21 }\end{array}$ & $\begin{array}{c}\text { Organización de } \\
\text { Estados Americanos }\end{array}$ & Junio 2019 \\
\hline $\begin{array}{c}\text { Informe de la Secretaría General } \\
\text { de la Organización de los Estados } \\
\text { Americanos y del panel de Expertos } \\
\text { Internacionales Independientes sobre la } \\
\text { posible comisión de crímenes de lesa } \\
\text { humanidad en Venezuela. OEA/Ser.D/ } \\
\text { XV.19 }\end{array}$ & $\begin{array}{c}\text { Organización de } \\
\text { Estados Americanos }\end{array}$ & 15 de julio de 2018 \\
\hline Declaraciones del Grupo de Lima & Grupo de Lima & $\begin{array}{l}\text { Agosto } 2017 \\
\text { Septiembre } 2018 \\
\text { Febrero } 2019 \\
\text { Mayo } 2019 \\
\end{array}$ \\
\hline $\begin{array}{c}\text { Institucionalidad democrática, Estado } \\
\text { de Derecho y Derechos Humanos en } \\
\text { Venezuela. Informe de país. OEA/ } \\
\text { Ser.L/V/II }\end{array}$ & $\begin{array}{l}\text { Comisión } \\
\text { Interamericana de } \\
\text { Derechos Humanos }\end{array}$ & $\begin{array}{l}31 \text { de diciembre de } \\
2017\end{array}$ \\
\hline
\end{tabular}

Elaboración propia.

\section{GRAVEDAD DE LOS DERECHOS VULNERADOS}

Un primer acercamiento es referirnos a la gravedad de los derechos vulnerados (Cuadro 2). En este sentido, todos los documentos arriba mencionados denuncian hechos que son referidos como delitos de lesa humanidad, torturas, ejecuciones sumarias, extralegales o arbitrarias, desapariciones forzadas y/o vulneraciones a los DESC.

En específico, respecto a la existencia de crímenes de lesa humanidad, el Grupo de Lima hace mención a este concepto en su declaración emitida el 03 de mayo de 2019, que fue firmada por los gobiernos de Argentina, Brasil, Canadá, Chile, Colombia, Costa Rica, Guatemala, Honduras, Panamá, Paraguay y Perú. En el punto 5 de dicho documento, se afirma lo siguiente:

"Deciden solicitar a la Corte Penal Internacional que tome en consideración la grave situación humanitaria en Venezuela, la violencia criminal del régimen de Nicolás Maduro 
en contra de la población civil, y la denegación del acceso a la asistencia internacional, que constituyen un crimen de lesa humanidad (...)" (resaltado nuestro).

Por lo tanto, los países que han firmado dicha declaración manifiestan claramente que consideran que la situación que vive Venezuela es especialmente grave y que algunos elementos podrían configurar crímenes de lesa humanidad: hechos que pueden y deben ser investigados por la Corte Penal Internacional ${ }^{82}$. Como se mencionaba en el apartado anterior, esta situación supone innegablemente que dichos países asumirían que existe una situación de "violación masiva de derechos humanos", elemento situacional recogido en la Declaración de Cartagena.

Por otro lado, los documentos analizados reportan diversos casos de detención arbitraria, otra violación considerada grave de acuerdo a lo analizado previamente. Así, en el informe elaborado por la CIDH a finales del 2017, ya se reportaban cerca de 12 mil personas que habrían sido detenidas ilegal y arbitrariamente desde enero de 2014 hasta 31 de octubre de $2017^{83}$. Dicha cifra es corroborada por el informe de la Organización de Estados Americanos (OEA) realizado en julio del 2018. Además, de acuerdo a esta organización, en los meses anteriores a la publicación del informe, se reportaron un mayor número de casos de desapariciones forzadas ${ }^{84}$. También se mencionan casos de mujeres de presuntos opositores políticos ${ }^{85}$ o de indígenas ${ }^{86}$ que han sido detenidas de manera arbitraria. Se puede observar que estas violaciones afectan de manera particular a ciertos grupos de la población como las mujeres, las personas indígenas o los opositores políticos. Así, este tipo de violación tiene un carácter masivo y configura una violación masiva de derechos humanos tal y como lo describimos anteriormente.

En cuanto a los casos de tortura, se denuncia que tanto el Servicio Bolivariano de Inteligencia Nacional (SEBIN) como la Dirección General de Contrainteligencia Militar (DGCIM) son los responsables de actos que pueden ser calificados como tortura y malos tratos. En ese sentido, los informes describen diversas formas de tortura utilizadas de manera habitual tanto por las fuerzas de seguridad como por los servicios de inteligencia mencionados para extraer información, confesiones e intimidar y sancionar a las personas detenidas ${ }^{87}$.

Otro aspecto que nos indica que se están produciendo "violaciones masivas de derechos humanos" en Venezuela es la constatación, en varios de los documentos analizados, de que se han producido hechos considerados como ejecuciones sumarias, extralegales o arbi-

\footnotetext{
82 Vale la pena mencionar que el 8 de febrero de 2018, la Fiscalía de la CPI anunció la apertura de un examen preliminar que analizaría la presunta comisión de crímenes internacionales desde abril de 2017. Más adelante, el 27 de septiembre, seis Estados americanos (Argentina, Canadá, Chile, Colombia, Paraguay y Perú) realizaron una remisión interestatal sobre la situación en Venezuela a la Fiscalía de la CPI, en aplicación del artículo $14^{\circ}$ del ER. Dichos Estados solicitaron a la Fiscal iniciar una investigación por la comisión de crímenes de lesa humanidad cometidos en el territorio de Venezuela desde el 12 de febrero de 2014. Para mayor información ver: https://www.icc-cpi.int/Pages/item.aspx?name=180927-otp-stat-venezuela

83 Comisión Interamericana de Derechos Humanos (2017) párr. 2013.

84 Organización de Estados Americanos (2018) p. 11.

85 Oficina de la Alta Comisionada de las Naciones unidas para los Derechos Humanos (2019) párr. 38.

86 Organización de Estados Americanos (2019) pp. 28-29.

87 Oficina de la Alta Comisionada de las Naciones unidas para los Derechos Humanos (2019) párr. 43; Comisión Interamericana de Derechos Humanos (2017) párr. 244.
} 
trarias. En 2017, ya la CIDH manifestó su preocupación por el aumento sostenido de las ejecuciones extrajudiciales ${ }^{88}$. En 2019, el Informe de la Alta Comisionada de las Naciones Unidas para los Derechos Humanos indica:

"El ACNUDH documentó los casos de seis hombres jóvenes ejecutados por las Fuerzas de Acción Especial de la Policía Nacional bolivariana (FAES) en represalia por su papel en las protestas antigubernamentales en 2019. Estas ejecuciones extrajudiciales tuvieron lugar durante allanamientos ilegales de domicilios después de las manifestaciones (...)" ${ }^{89}$.

Igualmente, se reportan casos de desapariciones forzadas. Así se destaca que en Venezuela las personas que son detenidas, en casi todos los casos, incluso siendo menores de edad, permanecen incomunicadas, en lugares desconocidos e impedidas del contacto con familiares y/o abogados. Consideran, por ello, que existen casos de desapariciones forza$\mathrm{das}^{90}$. Por lo tanto, existen indicadores contundentes de violaciones graves de derechos humanos en Venezuela reportados por parte de las Naciones Unidas, la Organización de Estados Americanos, la Comisión Internacional de Derechos Humanos y/o el Grupo de Lima.

\section{VIOLACIONES SISTEMÁTICAS Y/O MASIVAS}

Un segundo paso de cara a estudiar la existencia de "violaciones masivas de derechos humanos" en Venezuela, es analizar si las violaciones de derechos humanos pueden ser calificadas como sistemáticas y/o masivas (cuadro 2). En este sentido, cabe destacar que el Grupo de Lima, en su primera declaración conjunta en agosto de 2018, menciona específicamente que "condena la violación sistemática de los derechos humanos y las libertades fundamentales".

Asimismo, la OEA afirma que existen unos patrones sistemáticos de actuación por parte de los cuerpos de seguridad del Estado y de los tribunales a cargo de las causas que permiten afirmar que existe un "plan generalizado de detenciones y encarcelaciones arbitrarias en contra de cualquier que tenga una opinión contraria al Gobierno" ${ }^{11}$. Además, se destaca que existe un patrón de criminalización y privación de libertad de los alcaldes de la oposición. Dicho esquema, según la OEA incluye "1) arresto arbitrario; 2) detención ilegal; 3) aislamiento; 4) tortura; 5) trato cruel y degradante y encarcelamiento, y 6) denegación del derecho a un juicio imparcial y ausencia de cualquier apariencia de debido proceso: en particular, tener menos de 48 horas para preparar su defensa; la negativa de acceso a sus expedientes; la inexistencia del derecho de apelación; y la destitución arbitraria”. Ello sumado a que existiría hostigamiento a las familias y los hogares de los acusados por parte de agentes del SEBIN ${ }^{92}$.

Adicionalmente, la OEA, que solicitó un informe a un panel de expertos independientes, documenta diversas evidencias sobre "asesinatos, encarcelamientos, torturas, violaciones y otras formas de violencia sexual, persecución y desaparición forzada, que demuestran un patrón que evidencia la comisión de estos crímenes por parte del régimen”" ${ }^{\prime 3}$. Por lo

88 Comisión Interamericana de Derechos Humanos (2017) párr. 336.

89 Oficina de la Alta Comisionada de las Naciones unidas para los Derechos Humanos (2019) párr. 52.

90 Organización de Estados Americanos (2018) p. 193.

91 Organización de Estados Americanos (2018) p. 185.

92 Organización de Estados Americanos (2018) p. 31.

93 Organización de Estados Americanos (2019) p. 29. 
tanto, las violaciones mencionadas se han llevado a cabo de manera sistemática, siguiendo un patrón y planificación por parte del Estado.

En cuanto a la magnitud de las violaciones de derechos cometidos, es decir, si han afectado o no a la colectividad o a un grupo amplio, cabe mencionar que los números referidos en los documentos son sumamente altos. Entre otras cifras, se habla de casi 12 mil personas detenidas arbitrariamente entre el 1 de enero de 2014 y el 31 de octubre de $2017^{94}$ y de 8,292 asesinatos extrajudiciales cometidos ${ }^{95}$. En cuanto a torturas, el informe de la Secretaria de la OEA y del Panel de Expertos internacionales Independientes sobre la posible comisión de crímenes de lesa humanidad en Venezuela, presenta 72 casos de tortura, alguno de los cuales afecta a un conjunto de personas ${ }^{96}$.

Por último, debe mencionarse la existencia de violación de los DESC en Venezuela, teniendo en cuenta el espíritu de Cartagena. Los informes analizados presentan un panorama similar: una situación sumamente preocupante, empezando con un sueldo mínimo que no alcanza para las necesidades básicas, hecho que está generando un estado de desnutrición ${ }^{97}$ : "El Fondo de las Naciones Unidas para la Alimentación y la Agricultura reportó que 3.7 millones de venezolanos/as se encuentran en estado de desnutrición"98.

Además, el derecho a la salud no está garantizado debido a la carencia de fármacos e insumos en los hospitales ${ }^{99}$ y se ha producido un aumento en la mortalidad materna e infantil ${ }^{100}$. Así, "la Encuesta Nacional de Hospitales (2019) constató que, entre noviembre 2018 y febrero 2019, 1,557 personas murieron debido a la falta de insumos en hospitales" ${ }^{101}$. Existen también vulneraciones al derecho a la educación ${ }^{102}$. Por lo tanto, se ve que estas violaciones graves a los derechos económicos y sociales están afectando de forma generalizada a la población. Además, esta situación se ve agravada por el impedimento por parte del Gobierno de promover vías para la ayuda humanitaria ${ }^{103}$.

Se ha demostrado, por lo tanto, que según los elementos del cuadro № 2, en Venezuela se han dado una serie de violaciones a derechos consideradas como graves y que las características de estas violaciones son sistemáticas y generalizadas y ello es reconocido por un número amplio de Estados y de organismos supranacionales. En ese sentido, el elemento situacional de violación masiva debe aplicarse a las personas venezolanas desplazadas en América Latina.

\footnotetext{
94 Comisión Interamericana de Derechos Humanos (2017) p. 132.

95 Organización de Estados Americanos (2018) p. 11

96 Organización de Estados Americanos (2018) pp. 78-143.

97 Oficina de la Alta Comisionada de las Naciones unidas para los Derechos Humanos (2019) párr. 15; Organización de Estados Americanos (2019) pp. 26-27; Organización de Estados Americanos (2018) pp. 7, 260-261; Comisión Interamericana de Derechos (2017) p. 230.

98 Oficina de la Alta Comisionada de las Naciones unidas para los Derechos Humanos (2019) párr. 15.

99 Oficina de la Alta Comisionada de las Naciones unidas para los Derechos Humanos (2019) párr. 16, 19-20; Organización de Estados Americanos (2019) pp. 24-25; Organización de Estados Americanos (2018) pp. 251-253.

100 Oficina de la Alta Comisionada de las Naciones unidas para los Derechos Humanos (2019), párr.18; Organización de Estados Americanos (2019) p. 23; Organización de Estados Americanos (2018) p. 43.

101 Oficina de la Alta Comisionada de las Naciones unidas para los Derechos Humanos (2019), párr. 19.

102 Organización de Estados Americanos (2018), p. 35.

103 El Peruano (07/02/2019) sin paginación.
} 


\section{CONCLUSIONES}

A medida que el éxodo venezolano se expande, urge la necesidad de que los Estados se planteen la aplicación de la definición ampliada de Cartagena para garantizar a las personas una protección integral de sus derechos. El espíritu detrás de la adopción de una definición ampliada de refugiado refleja la necesidad de responder a flujos de desplazamiento cuyas causas no estaban previstas inicialmente por la Convención de 1951 y cuyas consecuencias son dramáticas no solo en términos numéricos, sino por las necesidades de protección de esta población. La definición de Cartagena con sus 5 elementos situacionales busca proteger a quienes no pueden serlo mediante la aplicación de la definición convencional. La intención de aplicar esta definición se ve reflejada en su incorporación en casi la totalidad de los marcos normativos sobre asilo de la región.

En ese marco, el artículo ofrece una reflexión sobre un elemento situacional previsto en la definición ampliada: la violación masiva de derechos humanos. Para ello, se han analizado primero los retos que enfrentan los sistemas de determinación de la condición de refugiado, así como la potencialidad del reconocimiento prima facie en casos en los cuales la evaluación individual es imposible. Debido a los altos números de solicitudes de refugio en Perú, Brasil, México, Costa Rica y Ecuador, y reconociendo las debilidades y limitaciones presupuestales de los sistemas de refugio en la región, la evaluación individual de cada solicitud en un plazo razonable se vuelve poco realista.

Segundo, partiendo de la naturaleza de la Declaración de Cartagena y el uso de conceptos propios y no definidos por el Derecho Internacional, se ha construido una aproximación conceptual a la "violación masiva de derechos humanos". Esta aproximación es aplicable en otros contextos de protección internacional que retan la definición tradicional de refugiado. Es así que si bien la ausencia de una definición unívoca representa una serie de retos, también puede verse como una oportunidad para reflexionar desde el espíritu de la Declaración de Cartagena y las características de los desplazamientos actuales.

El posicionamiento político los Estados de la región, junto con los organismos internacionales y otros Estados, ha sido claro a la hora de denunciar la situación de violación de derechos humanos en Venezuela. Sin embargo, a nivel regional falta el reconocimiento de la condición de refugiado de personas venezolanas mediante la aplicación de la definición ampliada de Cartagena. Dar este paso significaría ser consecuente con lo planteado por el Grupo de Lima y por la remisión interestatal sobre la situación en Venezuela a la Fiscalía de la Corte Penal Internacional (CPI). Ello volvería a América Latina a un verdadero líder de la protección de refugiados basada en los derechos humanos.

No cabe duda de que más allá de las obligaciones jurídicas, existe un costo político de la aplicación de la definición ampliada de Cartagena. Los gobiernos temen que esto pueda llevar a una mayor afluencia de venezolanos a sus países, poniendo mayor presión en los servicios públicos que ya tienen un bajo rendimiento y agitando el sentimiento xenófobo ${ }^{104}$. Por ello, los Estados han preferido crear instrumentos alternativos de regulación migratoria, sobre los cuales pueden tener un mayor control, aunque existen algunas excep-

104 Freier (2018) sin paginación. 
ciones. México y Brasil aplican la definición de Cartagena ${ }^{105}$, y Colombia ha considerado aplicarla aunque haya decidido finalmente optar por un mecanismo de regularización migratoria $^{106}$. Mayor cooperación regional será esencial para alcanzar una respuesta conjunta y adherirse al espíritu de Cartagena. Aplicar Cartagena de manera conjunta mediante el reconocimiento prima facie fortalecería significativamente el marco de protección progresivo de la región. Ya que, si los países continúan resistiendo la aplicación de Cartagena, corren el riesgo de reducirla a simples palabras y escaparatismo.

\section{BIBLIOGRAFÍA CITADA}

Acosta, Diego y Freier, Luisa Feline (2015): “Turning the Immigration Policy Paradox Upside Down? Populist Liberalism and Discursive Gaps in South America”, International Migration Review, vol. 49, No 3: pp. 659-696.

Acosta, Diego, Blouin, Cécile y Freier, Luisa Feline (2019). La emigración venezolana: respuestas latinoamericanas", Documento de trabajo No 3. https://www.fundacioncarolina.es/wp-content/uploads/2019/04/DT_FC_03.pdf. Consulta: 29 de abril de 2020.

Acosta, Arcarazo Diego y Madrid, Sartoretto, Laura (2020) ¿Migrantes o refugiados? la Declaración de Cartagena y los venezolanos en Brasil HTTPS://Www.FUnDACIONCAROLINA.ES/WP-CONTENT/UPLOADS/2020/03/AC-9.2020.PDF. Consulta: 29 de abril de 2020.

Amnistía internacional (2020) Buscando refugio: Perú da la espalda a quienes huyen de VENEZUELA HTTPS://WWW.AMNESTY.org/es/DOCUMENTS/AMr46/1675/2020/ES/ CONSULTA: 29 DE ABRIL DE 2020.

AlberT, Matthew (2010): "Governance and prima facie refugee status determination: clarifying the boundaries of temporary protection, group determination, and mass influx", Refugee Survey Quarterly, vol. 29, No 1: pp. 61-91.

Alto Comisionado de las Naciones Unidas para los Refugiados (1992): "Manual de procedimientos y criterios para determinar la condición de refugiado en virtud de la Convención de 1951 y el Protocolo de 1967 sobre el estatuto de los refugiados". Disponible en: http://www.acnur.org/fileadmin/Documentos/BDL/2011/7575.pdf. Fecha de consulta: 24 de noviembre de 2018.

Alto Comisionado de las Naciones Unidas para los Refugiados (2013): “Interpretación de la definición ampliada de refugiado contenida en la Declaración de Cartagena sobre Refugiados de 1984". Trabajo presentado en la Reunión de expertos de ACNUR. Montevideo, Uruguay. Disponible en: https://www.acnur.org/fileadmin/Documentos/ BDL/2011/7575.pdf. Fecha de consulta: 24 de noviembre de 2018.

Alto Comisionado de las Naciones Unidas para los Refugiados (2015): "Directrices sobre protección internacional no. 11: Reconocimiento prima facie de la condición de refugiado". Disponible en: https://www.acnur.org/5c6c387a4.pdf

Alto Comisionado de las Naciones Unidas para los Refugiados (2016): "Directrices sobre protección internacional No 12, 2 de diciembre”. Disponible en: https://www.

105 SÁNCHEZ (2018) p. 12.

106 Blouin, Freier y Berganza (2020) sin paginación. 
refworld.org/cgi-bin/texis/vtx/rwmain/opendocpdf.pdf?reldoc=y\&docid=58c654244. Fecha de consulta: 24 de noviembre de 2018.

Alto Comisionado de las Naciones Unidas para los Refugiados (2018): “Asylum-seekers from Venezuela 2014-18”. Disponible en: https://data2.unhcr.org/en/situations/vensit. Fecha de consulta: 24 de noviembre de 2018.

Arboleda, Eduardo (1991): "Refugee Definition in Africa and Latin America: The Lessons of Pragmatism", International Journal of Refugee Law, vol. III, No 2: pp. 185-207.

Blouin, Cécile, Berganza, Isabel y Freier, Luisa Feline (2020): “The spirit of Cartagena? Applying the extended refugee definition to Venezuelans in Latin America" https:// www.fmreview.org/cities/blouin-berganza-freier. Consulta: 29 de abril de 2020

Berganza, Isabel (2016): Ciudadanía migrante, rutas, costos y dinámicas de los flujos mixtos en tránsito por Perú (Lima, UARM y Encuentros).

Cantor, David y Trimiño, Diana (2015): “¿Una solución simple para los refugiados que huyen de la guerra? La definición ampliada de América Latina y su relación con el derecho internacional humanitario", Anuario Mexicano de Derecho Internacional, vol. XV, No 1: pp. 165-194.

Carta a Fatou Bensouda, Fiscal de la Corte Penal Internacional (25 de septiembre de 2018). Disponible en. https://drive.google.com/file/d/1HRF5lvN18GaZP0W9J2xhIK Zj2xbt9H2N/view. Fecha de consulta: 24 de noviembre de 2018.

Ceriani Cernadas, Pablo (2018): "Migration Policies and Human Rights in Latin America: Progressive Practices, Old Challenges, Worrying Setbacks and New Threats". Disponible en: https://repository.gchumanrights.org/bitstream/handle/20.500.11825/629/ PolicyBrief_LatinAmerica_ok.pdf?sequence=4\&isAllowed=y. Fecha de consulta: 29 de abril de 2020.

Chernichenko, Stanislav (1993) "Definition of Gross and Large-scale Violations of Human Rights as an International Crime". Working Paper submitted in accordance with Sub-Commission on Prevention of Discrimination and Protection of Minorities Decision, UN doc. E/CN.4/Sub.2/1993/10, 8 June 1993, para. 42.

Comisión de Derechos Humanos de la Organización de las Naciones Unidas (1967) Resolución 8.

Consejo Económico y Social de la Organización de las Naciones Unidas (1967) Resolution 1235 (XLII).

Comisión Interamericana de Derechos Humanos (CIDH) (2018). Resolución 2/18: Migración forzada de personas venezolanas. Disponible en: https://www.oas.org/es/ cidh/decisiones/pdf/Resolucion-2-18-es.pdf. Fecha de consulta: 29 de abril de 2020.

Comisión Interamericana de Derechos Humanos (2016): "Informe Anual 2016". Disponible en: http://www.oas.org/es/cidh/docs/anual/2016/indice.asp. Fecha de consulta: 24 de noviembre de 2018.

Comisión Interamericana de Derechos Humanos (2017): "Institucionalidad democrática, Estado de derecho y derechos humanos en Venezuela". Disponible en: http://www. oas.org/es/cidh/informes/pdfs/Venezuela2018-es.pdf. Fecha de consulta: 24 de noviembre de 2018. 
Comisión Interamericana de Derechos Humanos. "Reglamento". Disponible en: http:// www.oas.org/es/cidh/mandato/Basicos/reglamentoCIDH.asp. Fecha de consulta: 24 de noviembre de 2018.

Convención Americana sobre Derechos Humanos, San José (22 de noviembre de 1969).

CuÉllar, Roberto et al. (1991): "Refugee and Related Developments in Latin America: Challenges Ahead”, International Journal of Refugee Law, vol. III, No 3: pp. 482-498.

Damrosh, Loris F. (2011): "Gross and Systematic Human Rights Violations", Max Planck Encyclopedia of Public International Law.

Declaración Conjunta 007 - 17, Lima, (8 de agosto de 2017).

Declaración de Cartagena sobre refugiados, Cartagena (19 al 22 de noviembre de 1984).

Declaración de la Fiscal de la Corte Penal Internacional, Sra. Fatou Bensouda,

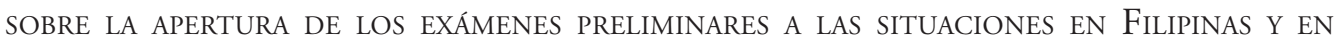
Venezuela (8 de febrero de 2018) Disponible en: https://www.icc-cpi.int/Pages/item. aspx?name=180208-otp-stat. Fecha de consulta: 24 de noviembre de 2018.

Declaración de la Fiscal de la Corte Penal Internacional, Sra. Fatou Bensouda, sobre la remisión de un grupo de seis Estados Partes sobre la situación en VeneZUELA (27 de septiembre de 2018) Disponible en: https://www.icc-cpi.int/Pages/item. aspx?name=180927-otp-stat-venezuela. Fecha de consulta: 24 de noviembre de 2018.

Durieux, Jean Francois (2008): "The Many Faces of "Prima Facie": Group-Based Evidence in Refugee Status Determination Refuge”, Canada's Journal on Refugees, vol. 25, No 2: 151-163. Disponible en: https://refuge.journals.yorku.ca/index.php/refuge/article/ view/26037

El Nacional (6/11/2019): “Colombia evalúa declarar a los migrantes venezolanos como refugiados". Disponible en: https://www.elnacional.com/mundo/colombia-evalua-declarar-a-los-migrantes-venezolanos-como-refugiados/

El Nacional (12/8/2019): “4 de cada 10 venezolanos planean irse del país”. Disponible en: https:/www.elnacional.com/venezuela/cuatro-de-cada-10-venezolanos-planea-irse-del-pais/

El Peruano (7/2/2019): "Maduro bloquea llegada de la ayuda humanitaria". Disponible en: https://www.elperuano.pe/noticia-maduro-bloquea-llegada-de-ayuda-humanitaria-75503.aspx

FisChel, José (2001): “Derechos de los Refugiados en América Latina: reflexiones sobre su futuro", en Naminas, Sandra (edit.), Derecho Internacional de los Refugiados (Lima, Fondo Editorial de la Pontificia Universidad Católica del Perú) pp. 191-223.

Fortin, Antonio (2005): "Doctrinal review of the broader refugee definition contained in the Cartagena Declaration”, en Memoria del Vigésimo Aniversario de la Declaración de Cartagena sobre los refugiados 1984-2004 (San José, Editorama), pp. 273-306.

Freier, Luisa Feline (2015): "A liberal paradigm shift? A Critical Appraisal of Recent Trends in Latin American Asylum Legislation”, en GAUCI, Jean-Pierre et al. (edits.), Exploring the boundaries of refugee law: current protection challenges (Boston, Brill Nijhoff).

FreIER, Luisa Feline (2018): "Why Latin America Should Recognize Venezuelans as Refugees”, Refugees Deeply. Disponible en: https://www.newsdeeply.com/refugees/community/2018/09/28/why-latin-america-should-recognize-venezuelans-as-refugees. Fecha de consulta: 24 de noviembre de 2018. 
Freier, Luisa Feline y Luzes, Marta (2020): "How humanitarian are humanitarian visas? An analysis of theory and practice in Latin America", en Jubilut, Liliana, Mezzanotti, Gabriela y Marcia Vera Espinoza, Marcia (edit.), Latin America and Refugee Protection: regimes, logics and challenges (Oxford, Berghahn). En prensa.

Galindo, Francisco (2001): "Consideraciones sobre la determinación de la condición de refugiado", en Naminas, Sandra (edit.), Derecho Internacional de los Refugiados (Lima, Fondo Editorial de la Pontificia Universidad Católica del Perú) pp. 93-188.

Geneva ACAdemy (2014): What amounts to a "serious violation of international human rights law"? An analysis of practice and expert opinion for the purpose of the 2013 Arms Trade Treaty. Disponible en: https:/www.geneva-academy.ch/joomlatools-files/docmanfiles/Publications/Academy\%20Briefings/Briefing $\% 206 \% 20$ What $\% 20$ is $\% 20$ a $\% 20$ serious $\% 20$ violation $\% 20$ of $\% 20$ human $\% 20$ rights $\% 20$ law_Academy $\% 20$ Briefing $\% 20$ No\%206.pdf. Fecha de consulta: 16 de septiembre de 2019.

Goodwin-Gill, Guy y McAdam, Jane (2007): The Refugee in International Law. (Toronto, Oxford University Press, tercera edición).

Grupo de Expertos para la Conferencia Internacional sobre Refugiados CentroameriCANOS (1989): "Principios y criterios para la protección y asistencia a los refugiados, repatriados y desplazados centroamericanos en América Latina”. Conferencia Internacional sobre Refugiados Centroamericanos. Ciudad de Guatemala, Guatemala.

Hossain Bhuiyan, Jahid (2013): "Refugee Status Determination: Analysis and Application”, en Rafiqul, Islam y Jahid Hossain Bhuiyan (edits.), An Introduction to International Refugee Law (Boston, Brill Nijhoff) pp. 37-72.

LetTieri, Martin (2012): "Procedimientos de determinación del estatuto de refugiado y cuestiones de prueba”, en LetTierri, Martin (edit.), Protección Internacional de Refugiados en el Sur de Sudamérica (Buenos Aires: Universidad Nacional de Lanús).

Lyra, Liliana; Sombra, Camila y Marques, Gilberto (2016): "Human Rights in Refugee Protection in Brazil", en Burson, Bruce y Cantor, David James (edits.), Human Rights and the Refugee Definition (Boston, Brill Nijhoff) pp. 210-228.

Mondelli, Juan Ignacio (2018) La fuerza vinculante de la definición regional de la Declaración de Cartagena sobre Refugiados (1984). Disponible en: https://www.refworld.org.es/ pdfid/5d03d0654.pdf.

Murillo, Juan (2004): "La importancia de la declaración de Cartagena sobre refugiados de 1984 al conmemorarse su vigésimo aniversario". Ponencia presentada en el Seminario Regional de la Asociación Internacional de Jueces de Derecho Internacional de Refugiados. San José, Costa Rica. Disponible en: https://www.acnur.org/fileadmin/Documentos/ BDL/2005/3124.pdf. Fecha de consulta: 24 de noviembre de 2018.

Oficina de la Alta Comisionado de las Naciones unidas para los Derechos Humanos (ACNUdH) (2019): Informe de la Alta Comisionada de las Naciones Unidas para los Derechos Humanos sobre la situación de los derechos humanos en la República Bolivariana de Venezuela*. Disponible en: https://www.ohchr.org/SP/NewsEvents/Pages/DisplayNews.aspx?NewsID=24788\&LangID=S. Fecha de consulta: 12 de mayo de 2020.

Organización de los Estados Americanos (2018): Informe de la secretaría general de la organización de los estados americanos y del panel de expertos internacionales in- 
dependientes sobre la posible comisión de crímenes de lesa humanidad en Venezuela Disponible en: https://reliefweb.int/sites/reliefweb.int/files/resources/Informe-PanelIndependiente-Venezuela-ES.pdf

Organización de los Estados Americanos (2019): Informe del Grupo de Trabajo de la Organización de Estados Americanos para abordar la crisis de migrantes y refugiados venezolanos en la Región. Disponible en: http://www.oas.org/documents/spa/press/OEAinforme-migrantes-venezolanos-espanol.pdf

Organización Internacional para las Migraciones (2018): "UN Migration Agency Releases First Displacement Tracking Matrix Results on Venezuelan Flows in Brazil". Comunicado de prensa del 27 de abril. Disponible en: https://www.iom.int/news/unmigration-agency-releases-first-displacement-tracking-matrix-results-venezuelan-flowsbrazil. Fecha de consulta: 24 de noviembre de 2018.

Organización Internacional para las Migraciones (2018): “Tendencias migratorias en las Américas. República Bolivariana de Venezuela”. Disponible en: https://robuenosaires.iom.int/sites/default/files/Informes/Tendencias_Migratorias_Nacionales_en_Americas_Venezuela-Septiembre_2018.pdf. Fecha de consulta: 24 de noviembre de 2018.

Organización Internacional para las Migraciones (2018): "Monitoreo de flujo de migración venezolana en el Perú. Matriz de Seguimiento del Desplazamiento". Disponible en: https://migration.iom.int/system/tdf/reports/DTM\%20R3_JULIO2018_\%20EN. pdf?file=1\&type $=$ node $\&$ id $=3945$. Fecha de consulta: 24 de noviembre de 2018 .

Plataforma Regional de Coordinación Interagencial para Refugiados y Migrantes de Venezuela (2019): "Refugiados y migrantes de Venezuela”. Disponible en: https://r4v. info/es/situations/platform. Fecha de consulta: 28 de octubre de 2019.

Protocolo de sobre el Estatuto de los Refugiados de 1967, Nueva York (31 de enero de 1967).

Resolución 1235 (xlit) del Consejo Económico y Social de la Organización de las NACIONES Unidas: "Cuestión de la violación de los derechos humanos y de las libertades fundamentales, incluso la política de discriminación racial y de segregación y la política de apartheid, en todos los países y en particular en los países y territorios coloniales y dependientes", (6 de junio de 1967).

Resolución 2929 de la AsAmblea General de la OEA: "Resolución sobre la situación en Venezuela", AG/RES. 2929 (5 de junio de 2018).

SÁnchez, Felipe (2018) "Declaración de Cartagena en México: 34 años de distanciamiento entre ley y práctica”. Disponible en: https://asiloenmexico.ibero.mx/informes/declaracion-de-cartagena-en-mexico/. Fecha de consulta: 17 de noviembre de 2019.

\section{NORMAS CITADAS}

Argentina. Ley No 26 165/2006, Ley de reconocimiento de protección al refugiado.

Bolivia. Ley No 251/2012, Ley de protección a personas refugiadas.

Brasil. Ley No 9 474/1997, Define mecanismos para a implementação do Estatuto dos Refugiados de 1951, e determina outras providências.

Chile. LEY No 20 430/2010, Establece disposiciones sobre protección de refugiados. 
Colombia. Decreto No 2 840/2013, Establece el procedimiento para el reconocimiento de la condición de refugiado, se dictan normas sobre la Comisión Asesora para la Determinación de la Condición de Refugiado y otras disposiciones. Costa Rica. LeY No 8 764/2009, Ley general de migración y extranjería.

Ecuador. DeCRETO No 1 182/2012, Reglamento para la aplicación del derecho de refugio.

El Salvador. Decreto No 918/2002, Ley para la determinación de la condición de personas refugiadas.

Guatemala. Acuerdo Gubernamental No 383/2001, Reglamento para la protección y determinación del estatuto de refugiado en el territorio del Estado de Guatemala.

Honduras. DeCReto No 208/2004, Ley de migración y extranjería.

México. Ley sobre refugiados y protección complementaria de 2011.

Nicaragua. LEY No 655/2008, Ley de protección a refugiados.

Panamá. Ley No 74/2013, Establece los requisitos para que todos los refugiados y asilados puedan aplicar a la categoría de residente permanente.

Paraguay. Ley No 1 938/2002, Ley general sobre refugiado.

Perú. Constitución Política del Perú de 1993.

Perú. Decreto Supremo No 135-2010-RE, Aprueba Reglamento de Organización y Funciones del Ministerio de Relaciones Exteriores.

Perú. Ley No 27 891/2002, Ley del Refugiado.

Uruguay. LEY No 18 076/2006, Estatuto del Refugiado.

Venezuela. LeY No 37 296/ 2001, Ley Orgánica sobre refugiados o refugiadas y asilados o asiladas.

\section{JURISPRUDENCIA CITADA}

Caso de los "Niños de la Calle" (Villagrán Morales y otros) vs. Guatemala. Corte Interamericana de Derechos Humanos. Sentencia del 19 de noviembre 1999.

Caso Barrios Altos vs. Perú. Corte Interamericana de Derechos Humanos. Sentencia del 14 de marzo de 2001. Serie C No 75.

Caso Almonacid Arellano y otros vs. Chile. Corte Interamericana de Derechos Humanos. Sentencia de 26 de setiembre de 2006. Serie C No 1540

Caso de la Masacre de Las Dos Erres vs. Guatemala. Corte Interamericana de Derechos Humanos. Sentencia del 24 de noviembre de 2009. Serie C No 211.

Caso Anzualdo Castro vs. Perú. Corte Interamericana de Derechos Humanos. Sentencia del 22 de septiembre de 2009. Serie C No 202.

Caso del Tribunal Constitucional (Camba Campos y otros) vs. Ecuador. Corte Interamericana de Derechos Humanos. Sentencia del 28 de agosto de 2013. Serie C No 268.

Caso Familia Pacheco Tineo vs. Estado Plurinacional de Bolivia. Corte Interamericana de Derechos Humanos. Sentencia del 25 de noviembre de 2015. Serie C No 272. 2.

Caso Lagos del Campo vs. Perú. Corte Interamericana de Derechos Humanos. Sentencia del 31 de agosto de 2017. Serie C No 340. 